\title{
Developing your communication skills in social work
}

\author{
Paula Beesley, Melanie Watts and Mary Harrison, 2018 \\ Sage Publishing; Thousand Oaks, CA \\ ISBN 9781473975873, pp. 176, paperback, NZD64.35
}

0 ocial workers know the importance of good communication.

An initial glance at the cover of this book, which appears childish and is covered in bright patterns and decorations, I questioned its intended audience and at which age group it was targeted. The introduction promptly clarifies this, and managed to capture me by declaring that there are often significant consequences when communication is inadequate. Right from the beginning, the book stresses the need for clear communication and highlights some historic tragedies that have resulted from a breakdown in communication, whether in the moment or in terms of recordings.

Hailing from Leeds Beckett University in the UK, the authors of this book focus on the UK context, though they do specifically comment on the need for social workers practising in Aotearoa New Zealand to match their ideas and recommendations against Aotearoa New Zealand registration, competencies and legislation.

Skillful communication begins with open questions, ensuring all parties are actively listening, clarifying and challenging where necessary. Social workers need to be confident that all decisions made reflect the needs of the people they are working with and to understand that service-users should be at the heart of communication. This book reminds us of the importance of social workers supporting people to identify their own strengths and weaknesses, and that good communication is key to achieving this. True partnership can only be achieved when social workers are communicating effectively.

The book includes a range of exercises to better enable to reader to reflect on their communication skills. The authors clarify that readers do not have to follow every exercise as shown; they are tools which can be adapted to a variety of contexts. The exercises cover links to knowledge and skills, activities, case studies, reflection and a personal final reflection/audit tool.

Early on in the book, the authors introduce the concept of emotional intelligence and how emotions affect communication. They recommend that student social workers spend 15 minutes a day to reflect on their learning and practice, and to make this a routine. One particularly useful tool is provided: Gibbs' reflective cycle diagram, which is a helpful summary of the social work reflection process (Gibbs, 1988).

Activities and tasks in this chapter provide valuable exercises for students and experienced social work practitioners.

The first part of the book covers concepts such as emotional intelligence; active listening and understanding; and empathy, and how best to apply these concepts in a professional social work context. One particularly interesting early chapter addresses the importance of initial engagements, making clear that social workers never get a second chance to make a first impression. Practical tips are included, such as providing serviceusers with written summaries of any 
discussion, to avoid misunderstandings and miscommunications. Chapter 4 includes a communication skills audit tool (see p. 67), which guides readers to identify their own strengths and areas which may need some professional development.

The authors go on to discuss potential challenges for communication between social workers and other parties, specifically how best to communicate constructively, while remaining mindful of the power differentials between social worker and service-user. One chapter focuses on working with people who are for whatever reason reluctant or unable to engage well with social workers. This includes attitudes and behaviour often seen at times of high stress. This chapter presents activities and reflective tasks guiding the reader in methods of maintaining a rapport when facing resistance and returning wayward conversations to their purpose. This chapter also includes the issue of silence which is another way service-users can send a loud message to the social worker.

Next the book moves on specifically to written communication, covering not just case-notes, assessments and reports, but also letters, text messages, social media and email. A useful assessment and reportwriting checklist is included, which could prove to be a great tool for new social workers. The authors remind us that clearly and precisely-written documents avoid confusion and producing them is a key skill social workers must develop.

In a chapter called "Interpersonal Communication," the authors explore how each professional involved in a case adds their own pieces of information from which a holistic assessment can be built, like pieces of a jigsaw fitting together to reveal the whole picture. It describes the importance of inter-disciplinary work and how these relationships might add complexity to a situation. The value of inter-disciplinary work has long been recognised, however, when different sectors of social services work together, everyone needs to remember keep the service user in mind. Reflective tasks and case studies allow readers to think about interpersonal communication and how the sharing of information between practitioners is essential for reflection, assessment, risk management and service provision.

The final chapter "Managing Endings" discusses the many different ways serviceusers can experience the process of ending a social work relationship. The authors stress that practitioners need to allow sufficient time to plan a process when ending a working relationship, and outline a variety of reasons for such an ending, including when goals are met, withdrawal, policy time limits, or limited resources. We are reminded that mixed emotions are to be expected as part of saying goodbye in a positive, helpful relationship. Reflection tasks are again provided for readers to explore occasions in their own lives and the lives of their clients, when positive endings have occurred. Saying goodbye is a final stage in evaluating the work a social worker has completed. This can also be a process for social workers and users to review how the user's skills can be used in the future to achieve other goals.

In conclusion, this is a great book for those starting out their social work careers. The book covers various communication (verbal, non-verbal and written) skills which social work students need to learn and understand while they working towards their qualification. If social workers move through this book to and engage with the case studies and reflective tasks, this can also develop emotional intelligence, which is a valuable tool. A final reflective task is included, with the aim of supporting readers to reflect on their progress throughout the book.

Though this book is clearly written with students in mind; it could also useful for experienced social workers to revise their knowledge and improve their practice, 
especially in the area of relatively newer communication skills related to professional use of social media. The book is clear that readers need to put in time and be motivated, as readers will only take away as much as they are prepared to put in and must continuously reflect on what they have learned.

\section{References}

Gibbs, G. (1988). Learning by doing: A guide to teaching and learning methods. London: Further Education Unit.

Reviewed by Megan Nayda, Social worker 